Check for updates

Cite this: RSC Adv., 2021, 11, 4465

Received 22nd September 2020 Accepted 13th November 2020

DOI: $10.1039 / \mathrm{d} 0 \mathrm{ra0} 08107 \mathrm{~h}$

rsc.li/rsc-advances

\title{
Study on the selective hydrogenation of isophorone $\uparrow$
}

\author{
Lei $\mathrm{Xu}^{\text {a }}$ Shaoyin Sun, ${ }^{\mathrm{b}}$ Xing Zhang, ${ }^{\mathrm{b}}$ Haofei Gao ${ }^{\mathrm{b}}$ and Wei Wang (D) *b
}

3,3,5-Trimethylcyclohexanone (TMCH) is an important pharmaceutical intermediate and organic solvent, which has important industrial significance. The selective hydrogenation of isophorone was studied over noble metal ( $\mathrm{Pd} / \mathrm{C}, \mathrm{Pt} / \mathrm{C}, \mathrm{Ir} / \mathrm{C}, \mathrm{Ru} / \mathrm{C}, \mathrm{Pd} / \mathrm{SiO}_{2}, \mathrm{Pt} / \mathrm{SiO}_{2}, \mathrm{Ir} / \mathrm{SiO}_{2}, \mathrm{Ru} / \mathrm{SiO}_{2}$ ), and non-noble metal (RANEY® $\mathrm{Ni}, \mathrm{RANEY} \circledast \mathrm{Co}, \mathrm{RANEY}{ }^{\circ} \mathrm{Cu}, \mathrm{RANEY}{ }^{\circledR} \mathrm{Fe}, \mathrm{Ni} / \mathrm{SiO}_{2}, \mathrm{Co} / \mathrm{SiO}, \mathrm{Cu} / \mathrm{SiO}_{2}, \mathrm{Fe} / \mathrm{SiO}_{2}$ ) catalysts and using solvent-free and solvent based synthesis. The results show that the solvent has an important effect on the selectivity of $\mathrm{TMCH}$. The selective hydrogenation of isophorone to $\mathrm{TMCH}$ can be influenced by the tetrahydrofuran solvent. The conversion of isophorone is $100 \%$, and the yield of 3,3,5trimethylcyclohexanone is $98.1 \%$ under RANEY ${ }^{\circledR} \mathrm{Ni}$ and THF. The method was applied to the selective hydrogenation of isopropylidene acetone, benzylidene acetone and 6-methyl-5-ene-2-heptanone. The structures of the hydrogenation product target (4-methylpentan-2-one, 4-benzylbutan-2-one and 6methyl-heptane-2-one) were characterized using ${ }^{1} \mathrm{H}-\mathrm{NMR}$ and ${ }^{13} \mathrm{C}-\mathrm{NMR}$. The yields of 4-methylpentan2-one, 4-benzylbutan-2-one and 6-methyl-heptane-2-one were 97.2\%, 98.5\% and 98.2\%, respectively. The production cost can be reduced by using RANEY ${ }^{\circledR}$ metal instead of noble metal palladium. This method has good application prospects.

\section{Introduction}

3,3,5-Trimethylcyclohexanone (TMCH) plays a vital role as a pharmaceutical intermediate, ${ }^{1}$ and a precursor to fuel, ${ }^{2-6}$ and can be used as a solvent for lacquers, varnishes, paints, vinyl resins and other coatings. ${ }^{5}$ Isophorone is the result of an acetone trimer ${ }^{7-12}$ that can be produced on an industrial scale using the acetone-butanol-ethanol (ABE) fermentation of lignocellulose.$^{13-15}$ Isophorone has a $\mathrm{C}=\mathrm{O}$ and a $\mathrm{C}=\mathrm{C}$ bond. Isophorone is specifically and selectively hydrogenated to $3,3,5-$ trimethylcyclohexanone. ${ }^{16}$ Isophorone is completely hydrogenated to produce 3,3,5-trimethyl cyclopentanol. ${ }^{17}$ The isophorone hydrogenation reaction route can be seen in Scheme 1 .

Typically, isophorone hydrogenation results in low isophorone conversion and a high TMCH selectivity. If the conversion of isophorone is high, the selectivity of TMCH is low, and the selectivity of 3,3,5-trimethylcyclohexanol is high. Since the boiling points of TMCH and 3,3,5-trimethylcyclohexanol are very similar $\left(190^{\circ} \mathrm{C}\right.$ and $195{ }^{\circ} \mathrm{C}$, respectively), it is difficult to separate TMCH and 3,3,5-trimethylcyclohexanol by distillation using the conventional physical analysis method. The

${ }^{a}$ School of Materials Science and Engineering, Shaanxi University of Technology, No. 1 Dongyihuan Road, Hanzhong, 723001, China

${ }^{b}$ Shaanxi Key Laboratory of Catalysis, School of Chemistry and Environment Science, Shaanxi University of Technology, Hanzhong, 723001, China.E-mail: wangwei@snut. edu.cn; Tel: +869162641660

$\dagger$ Electronic supplementary information (ESI) available. See DOI: 10.1039/d0ra08107h integration of high conversion of isophorone and high selectivity for TMCH is needed. Hence isophorone hydrogenation requires a highly selective and efficient process.

Solvents were added to increase the selectivity of the hydrogenation reaction. Sato et al. reported that isophorone hydrogenation was processed with supercritical carbon dioxide as a solvent, using noble metal catalysts (Pd, Pt and Ru are charged to activated carbon and alumina). Under $5 \% \mathrm{Pd} / \mathrm{Al}_{2} \mathrm{O}_{3}$, the conversion of isophorone was $99.9 \%$, and the yield of 3,3,5-trimethylcyclohexanone was $99.5 \% .^{2}$ On a supported palladium catalyst, the asymmetric hydrogenation of isophorone mediated by proline has a good enantioselectivity, and the enantiomeric excess rate can reach $99 \%$. The role of heterogeneous catalysts has always been a contentious topic and the conceptual model of the mechanism cannot interpret the observed enantioselectivity of the catalyst. ${ }^{4}$ Hou et al. demonstrated that Lewis acids could inhibit $\mathrm{C}=\mathrm{O}$ bond hydrogenation in the isophorone, thereby significantly increasing the selectivity towards

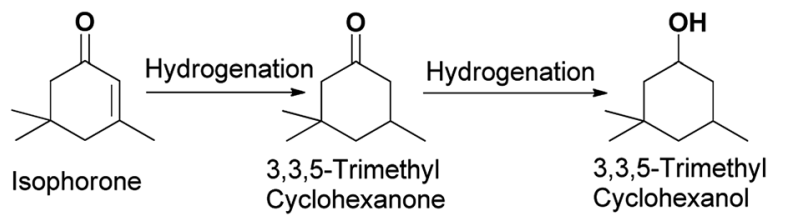

Scheme 1 Reaction route for the generation of 3,3,5-trimethylcyclohexanone and 3,3,5-trimethylcyclohexanol. 
TMCH. ${ }^{5}$ The conversion of isophorone and the selectivity of TMCH could be increased to more than $99 \%$ when zinc chloride, Pd/AC and dichloromethane were employed. PdNPs-SBA15 catalysts were prepared for the hydrogenation of $\alpha, \beta$-unsaturated carbonyl compounds to saturated carbonyl compounds. The conversion of isophorone was $100 \%$, meanwhile, the yield of 3,3,5-trimethylcyclohexanone was $100 \%$ on the PdNPs-SBA15 catalysts. ${ }^{17}$ Wang et al. reported that the hydrogenation of isophorone was conducted on a noble metal supported active carbon catalyst. The yield of 3,3,5-trimethylcyclohexanone was 99\%, under $\mathrm{Pd} / \mathrm{C}$ solvent-free conditions. ${ }^{6}$ A single capillary forward flow reactor (SCR) was built, constructed and evaluated for the selective hydrogenation of isophorone into trimethylcyclohexanone using commercial Rh- and Pd-based catalysts.

The reaction was carried out under the control of kinetics. Compared with the hydrogenation rate of the autoclave, the reaction rate of the capillary reactor was increased significantly. The reaction temperature is the key factor regulating the reaction of the different products. The calculated values of the constant relative reaction rate and the apparent activation energy under different catalyst loading values showed that the hydrogenation of isophorone in a single capillary reactor was not limited by mass transfer. ${ }^{18}$

The selective hydrogenation of isophorone (3,3,5-trimethyl2-enecyclohexanone) has been studied under $(S)$-proline modified Pd catalysts. The $\mathrm{Pd} / \mathrm{MgO}$ catalyst with moderate $\mathrm{Pd}$ particle sizes and the reinforced adsorption of proline resulted in a $43 \%$ yield of TMCH and a high enantioselectivity (ee of 95\%). ${ }^{1920}$ The $\mathrm{Pd} / \mathrm{Al}_{2} \mathrm{O}_{3}-\mathrm{K}_{2} \mathrm{CO}_{3}$ catalyst, with enhanced the adsorption of proline and finely dispersed Pd particles, provided very high enantioselectivities (ee 98\%) for the isophorone enantioselective hydrogenation. ${ }^{21}$ The chemical and diastereoselective hydrogenation of isophorone was proved to be the main source of trimethylcyclohexanone by the reaction rate, gas chromatography (GC), gas chromatography-mass spectrometry (GC-MS) and preparation experiments. ${ }^{21-23}$ It was stated that isophorone undergoes highly efficient asymmetric heterogeneous hydrogenation with a proline modified simple palladium catalyst. The powerful combination of the enhanced proline adsorption and kinetic second order resolution resulted in a rather high enantioselectivity (ee up to 99\%). Proline and the enantiomers were obtained with a high optical yield. ${ }^{24,25}$

Overall, in the process of TMCH synthesis from isophorone, the catalysts that exhibited a high conversion of isophorone and a high selectivity of TMCH were noble metals catalysts (Pd, Pt and $\mathrm{Ru}$ ). The production cost is high, which is not conducive to industrial applications. To solve the cost problem, we have attempted to use non-noble metals instead of noble metals.

In this work, the hydrogenation of isophorone to TMCH was studied over noble metal (Pd/C, Pt/C, Ir/C, Ru/C, Pd/SiO ${ }_{2}, \mathrm{Pt} /$ $\mathrm{SiO}_{2}, \mathrm{Ir} / \mathrm{SiO}_{2}, \mathrm{Ru} / \mathrm{SiO}_{2}$ ) and non-noble metal (RANEY® $\mathrm{Ni}$, RANEY® ${ }^{\circledR} \mathrm{Co}, \mathrm{RANEY}{ }^{\circledR} \mathrm{Cu}, \mathrm{RANEY}{ }^{\circledR} \mathrm{Fe}, \mathrm{Ni} / \mathrm{SiO}_{2}, \mathrm{Co} / \mathrm{SiO}_{2}, \mathrm{Cu} /$ $\mathrm{SiO}_{2}, \mathrm{Fe} / \mathrm{SiO}_{2}$ ) catalysts. The effect of the solvent effect on the selective hydrogenation of isophorone was researched. It was found that the solvent (tetrahydrofuran (THF), N,N-dimethyl formamide (DMF), ethyl acetate, chloroform, ethanol, methanol, isopropanol and propanol) inhibited the hydrogenation of the carbonyl group on isophorone. The results indicate that the non-noble metal + THF can encourage selective hydrogenation of the $\mathrm{C}=\mathrm{C}$ bond and inhibit $\mathrm{C}=\mathrm{O}$ double bond hydrogenation in isophorone. The production cost can be reduced by using RANEY ${ }^{\circledR}$ metal instead of noble metal palladium. This method has good application prospects and is conducive to industrial applications.

\section{Experimental}

\section{Materials}

Dalian Tongyun Chemical Co., Ltd supplied RANEY® Ni, RANEY ${ }^{\circledR}$ Co, RANEY® $\mathrm{Cu}$, and RANEY® Fe. The Pd/C catalyst used was produced for selective hydrogenation by incipient wetness impregnation of $\mathrm{HNO}_{3}$ treated active carbon with an aqueous $\mathrm{PdCl}_{2}$ solution. The $\mathrm{Pt} / \mathrm{C}$ catalyst used was prepared for selective hydrogenation through incipient wetness impregnation of $\mathrm{HNO}_{3}$ treated active carbon with an aqueous solution of $\mathrm{H}_{2} \mathrm{PtCl}_{6} \cdot 6 \mathrm{H}_{2} \mathrm{O}$. The Ir/C catalyst used was prepared for selective hydrogenation by incipient wetness impregnation of $\mathrm{HNO}_{3}$ treated active carbon with an aqueous solution of $\mathrm{H}_{2} \mathrm{IrCl}_{6}$ $\cdot 6 \mathrm{H}_{2} \mathrm{O}$. The $\mathrm{Ru} / \mathrm{C}$ catalyst used was prepared by incipient wetness impregnation of $\mathrm{HNO}_{3}$ treated active carbon with an aqueous solution of $\mathrm{RuCl}_{3} \cdot 3 \mathrm{H}_{2} \mathrm{O}$ for selective hydrogenation. The as-obtained catalyst precursors were dried for $24 \mathrm{~h}$ at $353 \mathrm{~K}$ and then reduced using $\mathrm{H}_{2}\left(160 \mathrm{~mL} \mathrm{~min}^{-1} \mathrm{~g}_{\text {cat }}{ }^{-1}\right)$ for $2 \mathrm{~h}$ at 623 $\mathrm{K}$. The catalysts were passivated with 1 vol\% $\mathrm{O}_{2}$ in $\mathrm{N}_{2}$ after cooling in $\mathrm{H}_{2}$ to room temperature. The metal content in each catalyst was set at $5 \%$ by weight (referred to as $5 \mathrm{wt} \%$ ) to allow comparison.

The $\mathrm{Ni} / \mathrm{SiO}_{2}$ catalyst utilized in the selective hydrogenation step was prepared using a previously reported ${ }^{26}$ impregnation $^{2}$ method. The $\mathrm{Ni} / \mathrm{SiO}_{2}, \mathrm{Co} / \mathrm{SiO}_{2}, \mathrm{Cu} / \mathrm{SiO}_{2}, \mathrm{Fe} / \mathrm{SiO}_{2}, \mathrm{Pd} / \mathrm{SiO}{ }_{2}, \mathrm{Pt} /$ $\mathrm{SiO}_{2}, \mathrm{Ir} / \mathrm{SiO}_{2}$ and $\mathrm{Ru} / \mathrm{SiO}_{2}$ catalysts used in the selective hydrogenation process were prepared using incipient wetness impregnation of $\mathrm{SiO}_{2}$ with an aqueous solution of $\mathrm{Ni}\left(\mathrm{NO}_{3}\right)_{3}$ $\cdot 6 \mathrm{H}_{2} \mathrm{O}, \quad \mathrm{Co}\left(\mathrm{NO}_{3}\right)_{3} \cdot 6 \mathrm{H}_{2} \mathrm{O}, \quad \mathrm{Cu}\left(\mathrm{NO}_{3}\right)_{2} \cdot 6 \mathrm{H}_{2} \mathrm{O}, \quad \mathrm{Fe}\left(\mathrm{NO}_{3}\right)_{3} \cdot 9 \mathrm{H}_{2} \mathrm{O}$, $\mathrm{PdCl}_{2}, \mathrm{H}_{2} \mathrm{PtCl}_{6} \cdot 6 \mathrm{H}_{2} \mathrm{O}, \mathrm{H}_{2} \mathrm{IrCl}_{6} \cdot 6 \mathrm{H}_{2} \mathrm{O}$ or $\mathrm{RuCl}_{3} \cdot 3 \mathrm{H}_{2} \mathrm{O}$. The metal content in each catalyst was set at $5 \mathrm{wt} \%$ to allow comparison. The catalysts were reduced using hydrogen flow on line at $623 \mathrm{~K}$ for $2 \mathrm{~h}$ after drying at $353 \mathrm{~K}$ for $4 \mathrm{~h}$.

\section{Hydrogenation of isophorone with solvent-free synthesis}

The direct synthesis of 3,3,5-trimethylcyclohexanone using the selective hydrogenation of isophorone and hydrogen was performed using a polytetrafluoroethylene coated stainless steel batch reactor. Isophorone, $1.16 \mathrm{~g}, 2.0 \mathrm{MPa} \mathrm{H}_{2}$, and $0.05 \mathrm{~g}$ of the catalyst were used for each test. The stainless steel batch reactor was purged using nitrogen three times before the test. The catalyst and reactant mixture was stirred for $120 \mathrm{~min}$ at $298 \mathrm{~K}$. The stainless steel reactor was subsequently quenched with ice. The liquid products were collected from the stainless steel batch reactor, poured by magnetic adsorption to remove the solid catalyst and analyzed using an Agilent 7890A gas chromatograph equipped with a capillary column of HP-INNOWAX (30 m, $0.25 \mathrm{~mm} \mathrm{ID,} 0.5 \mathrm{~mm}$ film) and a flame ionizing 
detector (FID). The oven temperature was held for $2 \mathrm{~min}$ at 313 $\mathrm{K}$, raised to $553 \mathrm{~K}$ at a rate of $15 \mathrm{~K} \mathrm{~min}^{-1}$, and remained at that temperature for $5 \mathrm{~min}$. Helium was used at a flow rate of 1.5 $\mathrm{mL} \min ^{-1}$ as the carrier gas.

\section{Hydrogenation of isophorone with solvent}

The hydrogenation of the isophorone reaction with a solvent was processed with a polytetrafluoroethylene coated stainless steel batch reactor. The other conditions were kept the same as the solvent-free hydrogenation, except for adding $10 \mathrm{~mL}$ solvent. The solvents involved in the reaction were THF, DMF, ethyl acetate, chloroform, ethanol, methanol, isopropanol and propanol.

\section{Results and discussion}

\section{Synthesis of 3,3,5-trimethylcyclohexanone}

3,3,5-Trimethylcyclohexanone is mainly used as a good solvent for nitrocellulose, low molecular weight polyvinyl chloride, alkyd resin and other substances. It is also an important intermediate for pharmaceutical synthesis, that is mainly used in the fields of medicine, pesticides, and so on. The derivatives of 3,3,5-trimethylcyclohexanone are widely used and have a high added value. They can be used in pigment and coating industries. Therefore, in recent years, it has received the attention of scholars at home and abroad.

\section{Hydrogenation solvent-free}

Hydrogenation is an important kind of reaction, which can be carried out under solvent or solvent-free conditions. A solventfree reaction can increase the feed rate, reduce energy consumption and improve production efficiency, which conforms to the principles of green chemistry. According to analysis of the GC (Fig. S1 $\dagger$ ) and NMR (Fig. S2 and S3 $\dagger$ ) spectra, 3,3,5-trimethylcyclohexanone (in Schemes 1 and 2) was identified as the main product under Pd/C. The NMR spectra (Fig. S2 $\dagger$ ) of 3,3,5-trimethylcyclohexanone show the following peaks: ${ }^{1} \mathrm{H}$ NMR $\left(\mathrm{CDCl}_{3}-\mathrm{d}\right), \delta: 2.27-2.30(\mathrm{~m}, 1 \mathrm{H}), 2.11-2.14(\mathrm{~d}$, $1 \mathrm{H}, J=12), 1.98-2.05(\mathrm{~m}, 2 \mathrm{H}), 1.83-1.88$ (s, 1H), 1.54-1.56 (d, $1 \mathrm{H}, J=8), 1.24-1.29(\mathrm{t}, 1 \mathrm{H}), 1.03(\mathrm{~s}, 3 \mathrm{H}), 0.98-1.00(\mathrm{~d}, 3 \mathrm{H}, J=8)$,

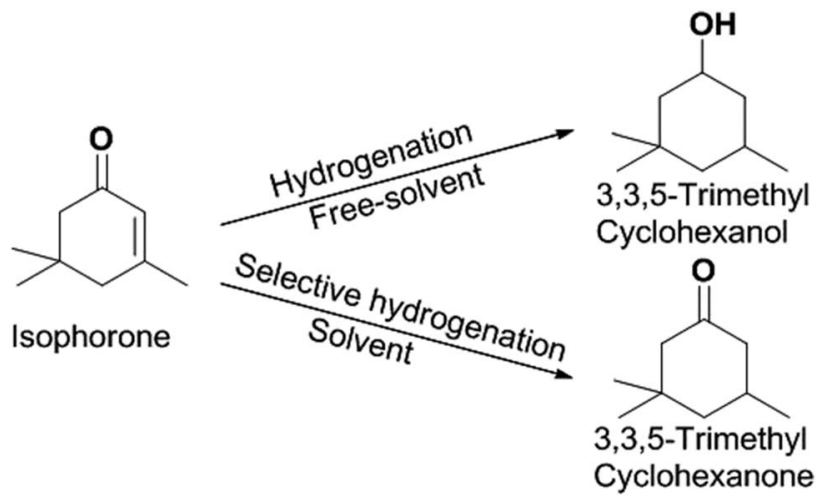

Scheme 2 Reaction route for the generation of 3,3,5-trimethylcyclohexanone and 3,3,5-trimethylcyclohexanol.
0.86 (s, 3H); ${ }^{13} \mathrm{C}$ NMR (CDCl3-d), $\delta: 211.5$ (1C), 54.2 (1C), 49.2 (1C), 47.2 (1C), 35.4 (1C), 32.1 (1C), 29.5 (1C), 25.7 (1C), 22.3 (1C). 3,3,5-Trimethylcyclohexanone is a colorless liquid. The NMR spectra (Fig. S3 $\dagger$ ) of 3,5,5-trimethylcyclohexanol show the following peaks: ${ }^{1} \mathrm{H} \mathrm{NMR}\left(\mathrm{CDCl}_{3}-\mathrm{d}\right), \delta: 4.24(\mathrm{~s}, 1 \mathrm{H}), 1.82-1.85(\mathrm{~d}$, $1 \mathrm{H}, J=12), 1.62-1.64(\mathrm{~d}, 1 \mathrm{H}, J=8), 1.50-1.53(\mathrm{~m}, 1 \mathrm{H}), 1.37-1.39$ $(\mathrm{d}, 1 \mathrm{H}, J=8), 1.20(\mathrm{~s}, 3 \mathrm{H}), 0.97(\mathrm{~d}, 6 \mathrm{H}), 0.90-0.94(\mathrm{~m}, 1 \mathrm{H}) ;{ }^{13} \mathrm{C}$ NMR ( $\mathrm{CDCl}_{3}$-d), $\delta$ : 68.1 (1C), 48.4 (1C), 44.7 (1C), 41.4 (1C), 33.9 (1C), 30.6 (1C), 28.0 (1C), 22.7 (1C), 22.4 (1C). 3,5,5-Trimethylcyclohexanol was obtained as white needle crystals. The solvent-free hydrogenation of isophorone was carried out on noble metal (Pd/C, Pt/C, Ir/C, Ru/C, Pd/SiO ${ }_{2}, \mathrm{Pt} / \mathrm{SiO}_{2}, \mathrm{Ir} / \mathrm{SiO}_{2}$, $\mathrm{Ru} / \mathrm{SiO}_{2}$ ) and non-noble metal (RANEY® nickel, RANEY® cobalt, RANEY® copper, RANEY ${ }^{\circledR}$ iron, $\mathrm{Ni} / \mathrm{SiO}_{2}, \mathrm{Co} / \mathrm{SiO}_{2}, \mathrm{Cu} /$ $\mathrm{SiO}_{2}, \mathrm{Fe} / \mathrm{SiO}_{2}$ ) catalysts. The reaction results are shown in Fig. 1 and 2 , respectively.

Fig. 1 shows that the order of hydrogenation activity of the catalysts is: $\mathrm{Pd} / \mathrm{C} \approx \mathrm{Pd} / \mathrm{SiO}_{2}>\mathrm{Ir} / \mathrm{C}>\mathrm{Ir} / \mathrm{SiO}_{2}>\mathrm{Pt} / \mathrm{C}>\mathrm{Pt} / \mathrm{SiO}_{2}>\mathrm{Ru} /$ $\mathrm{C} \approx \mathrm{Ru} / \mathrm{SiO}_{2} . \mathrm{Pd} / \mathrm{C}$ and $\mathrm{Pd} / \mathrm{SiO}_{2}$ showed the best activity and selectivity. The conversion of isophorone was over $99.7 \%$, and the yield of 3,3,5-trimethylcyclohexanone was over $99.4 \%$. The $\mathrm{C}=\mathrm{C}$ double bond and $\mathrm{C}=\mathrm{O}$ double bond in isophorone were not selective over the $\mathrm{Ir} / \mathrm{C}, \mathrm{Ru} / \mathrm{C}, \mathrm{Pd} / \mathrm{SiO}_{2}, \mathrm{Pt} / \mathrm{SiO}_{2}, \mathrm{Ir} / \mathrm{SiO}_{2}$ and $\mathrm{Ru} / \mathrm{SiO}_{2}$ catalysts. The catalytic activity of $\mathrm{Ru} / \mathrm{C}$ and $\mathrm{Ru} / \mathrm{SiO}_{2}$ were the lowest. The conversion of isophorone was only $3.1 \%$.

Fig. 2 shows that the order of the hydrogenation activity of the catalysts was $\mathrm{RANEY}{ }^{\circledR}$ nickel $\approx \mathrm{Ni} / \mathrm{SiO}_{2}>\mathrm{RANEY}{ }^{\circledR}$ cobalt $\approx$ $\mathrm{Co} / \mathrm{SiO}_{2}>\mathrm{RANEY}{ }^{\circledR}$ copper $\approx \mathrm{Cu} / \mathrm{SiO}_{2}>\mathrm{RANEY}{ }^{\circledR}$ iron $\approx \mathrm{Fe} /$ $\mathrm{SiO}_{2}$. RANEY® nickel showed the best activity. The conversion of isophorone was $99.8 \%$ under RANEY® nickel, the yields of TMCH and 3,3,5-trimethylcyclohexanol were $72.5 \%$ and $26.5 \%$, respectively. $\mathrm{Ni} / \mathrm{SiO}_{2}$ and $\mathrm{RANEY}{ }^{\circledR}$ nickel have a similar catalysis reaction activity and selectivity. RANEY® cobalt and $\mathrm{Co} / \mathrm{SiO}_{2}$ also have better catalytic activity and selectivity. The conversion of isophorone was above $83.4 \%$, and the yield of TMCH was above $62.5 \%$. The catalytic activity and selectivity of RANEY® iron and $\mathrm{Fe} / \mathrm{SiO}_{2}$ were the weakest, and the conversion of

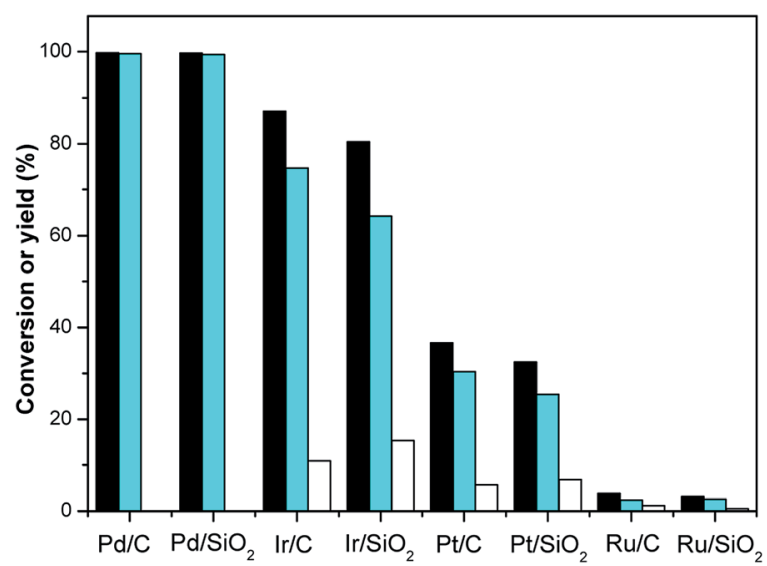

Fig. 1 Isophorone conversions (black bars) and the carbon yields of TMCH (cyan bars), and 3,3,5-trimethylcyclohexanol (white bars) under the different catalysts. Reaction conditions: $1.16 \mathrm{~g}$ isophorone, $0.05 \mathrm{~g}$ catalysis, 2.0 MPa $\mathrm{H}_{2} ; 298 \mathrm{~K}, 1 \mathrm{~h}$. 


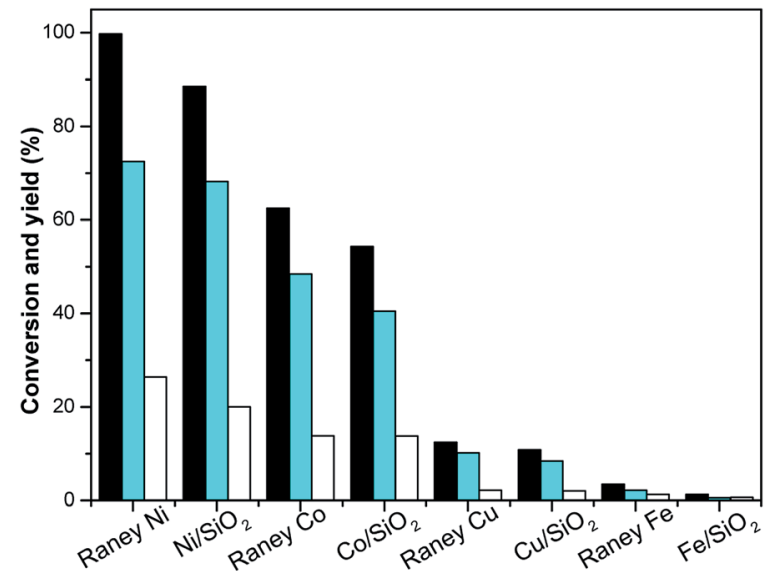

Fig. 2 Isophorone conversions (black bars) and the carbon yields of TMCH (cyan bars), and 3,3,5-trimethylcyclohexanol (white bars) under the different catalysts. Reaction conditions: $1.16 \mathrm{~g}$ isophorone, $0.05 \mathrm{~g}$ catalyst, $2.0 \mathrm{MPa} \mathrm{H}_{2} ; 298 \mathrm{~K}, 1 \mathrm{~h}$.

isophorone was below $3.5 \%$. The hydrogenation of the $\mathrm{C}=\mathrm{C}$ double bond and $\mathrm{C}=\mathrm{O}$ double bond in isophorone was not selective over RANEY® nickel, RANEY® cobalt, RANEY® copper, RANEY® iron, $\mathrm{Ni} / \mathrm{SiO}_{2}, \mathrm{Co} / \mathrm{SiO}_{2}, \mathrm{Cu} / \mathrm{SiO}_{2}$, and $\mathrm{Fe} / \mathrm{SiO}_{2}$ catalysts. The main product of isophorone hydrogenation is TMCH.

\section{Hydrogenation with solvent}

Many reactions are carried out in the presence of solvents. The effect of the solvent is not only to dissolve reactants, but also to interact with reactants. The proper choice of solvent can accelerate the main reaction and inhibit the side reaction effectively. Therefore, the influence of solvents in chemical reactions should not be underestimated, and should be paid attention to. The effects of THF, chloroform, DMF, ethyl acetate, ethanol, methanol, isopropanol and propanol on the selective

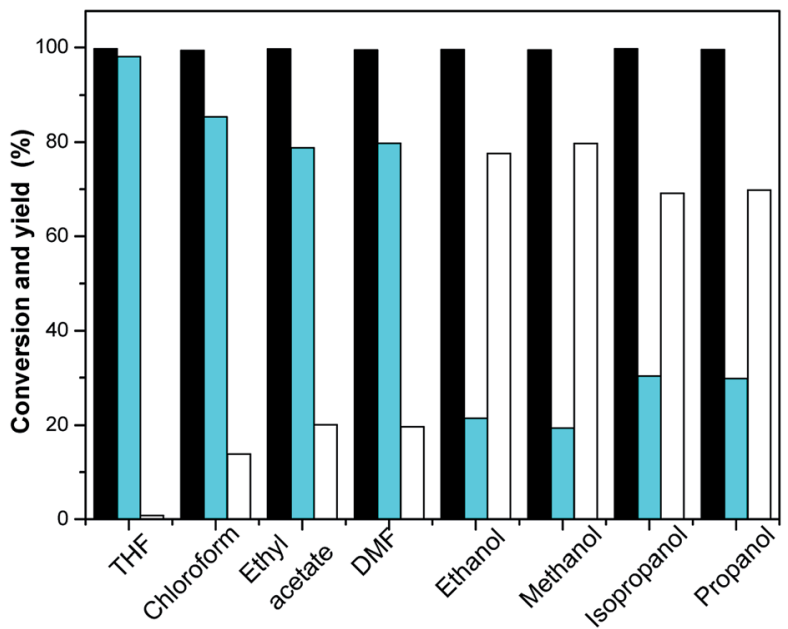

Fig. 3 Isophorone conversions (black bars) and the carbon yields of $\mathrm{TMCH}$ (cyan bars), and 3,3,5-trimethylcyclohexanol (white bars) under the different solvents. Reaction conditions: $298 \mathrm{~K}, 1 \mathrm{~h} ; 1.16 \mathrm{~g}$ isophorone, $0.05 \mathrm{~g}$ RANEY® Ni, $2.0 \mathrm{MPa} \mathrm{H}_{2}$. hydrogenation of isophorone were investigated. The reaction results are shown in Fig. 3. It can be seen from Fig. 3 that THF has a dramatic effect on the selective hydrogenation of isophorone. Under optimized conditions, the conversion of isophorone was $99.8 \%$, and the yields of $\mathrm{TMCH}$ and 3,3,5trimethylcyclohexanol were $98.1 \%$ and $0.8 \%$, respectively. Solvents such as chloroform, DMF and ethyl acetate promote the selectivity of TMCH from isophorone hydrogenation, and the yields of TMCH increased from $72.5 \%$ to $85.4 \%, 78.8 \%$ and $79.8 \%$, respectively. Solvents such as methanol, ethanol, isopropanol, and propanol promoted the selectivity of 3,5,5-trimethylcyclohexanol from isophorone hydrogenation, the yields of 3,5,5-trimethylcyclohexanol increased from $26.5 \%$ to $77.6 \%$, $79.7 \%, 69.1 \%$ and $69.8 \%$, respectively. Alcohols as solvents are favorable for the simultaneous hydrogenation of carbonyl and $\mathrm{C}=\mathrm{C}$ double bonds in $\alpha, \beta$-unsaturated aldehydes or ketones. ${ }^{27,28}$ Alcohols are used as hydrogen sources for selective hydrogenation. ${ }^{\mathbf{2 9 , 3 0}}$

The hydrogenation mechanisms of the $\mathrm{C}=\mathrm{C}$ double bond and $\mathrm{C}=\mathrm{O}$ double bond in unsaturated aldehydes and ketones are completely different. The hydrogenation of the $\mathrm{C}=\mathrm{C}$ double bond is performed on the active metal, while the hydrogenation of the $\mathrm{C}=\mathrm{O}$ double bond is performed between the support and the active metal. After adding the solvent, the $\mathrm{C}=\mathrm{O}$ double bond of the solvent and isophorone underwent competitive adsorption with the active center of the catalyst. The addition of THF, chloroform, DMF and ethyl acetate, the yield and selectivity of $\mathrm{TMCH}$ were improved by reducing the binding sites of the $\mathrm{C}=\mathrm{O}$ double bond with the active center of the catalyst in isophorone. In addition to the competitive adsorption between the $\mathrm{THF}$ and $\mathrm{C}=\mathrm{O}$ double bond, it is possible that the molecular volume of THF is larger and has a steric hindrance effect, which greatly improves the selectivity of TMCH. After the adsorption and activation of ethanol, methanol, isopropanol and propanol with the active center of the catalyst, hydrogen protons were dissociated, which is conducive to the hydrogenation of the $\mathrm{C}=\mathrm{O}$ double bond of isophorone, and the yield of 3,3,5-trimethylcyclohexanol is increased.

The effect of the reaction time on the selective hydrogenation activity of isophorone was investigated, as shown in Fig. 4. It can be seen from Fig. 4 that the conversion of isophorone first increases and then tends to be constant in the range of 10$240 \mathrm{~min}$, while the yield of 3,3,5-trimethylcyclohexanone increases first and then decreases slightly. When the reaction time was $120 \mathrm{~min}$, the conversion of isophorone was $99.8 \%$, and the yield of 3,3,5-trimethylcyclohexanone was $98.1 \%$. At a $240 \mathrm{~min}$ reaction time, the yield of 3,3,5-trimethylcyclohexanone and 3,3,5-trimethylcyclohexanol was $90.1 \%$ and $9.2 \%$, respectively. The best reaction time was found to be $120 \mathrm{~min}$.

The selective hydrogenation of isophorone over noble metal (Pd/C, Pt/C, Ir/C, Ru/C, Pd/SiO ${ }_{2}, \mathrm{Pt} / \mathrm{SiO}_{2}, \mathrm{Ir} / \mathrm{SiO}_{2}$ and $\mathrm{Ru} / \mathrm{SiO}_{2}$ ) and non-noble metal (RANEY® nickel, RANEY® cobalt, RANEY® copper, RANEY® iron, $\mathrm{Ni} / \mathrm{SiO}_{2}, \mathrm{Co} / \mathrm{SiO}_{2}, \mathrm{Cu} / \mathrm{SiO}_{2}$, and $\mathrm{Fe} / \mathrm{SiO}_{2}$ ) catalysts was investigated using THF as a solvent. The reaction results are shown in Fig. 5 and 6 respectively. It can be seen from Fig. 5 that the selective hydrogenation of the $\mathrm{C}=\mathrm{C}$ bond in isophorone was significant improved over the Ir/C, Ir/ 


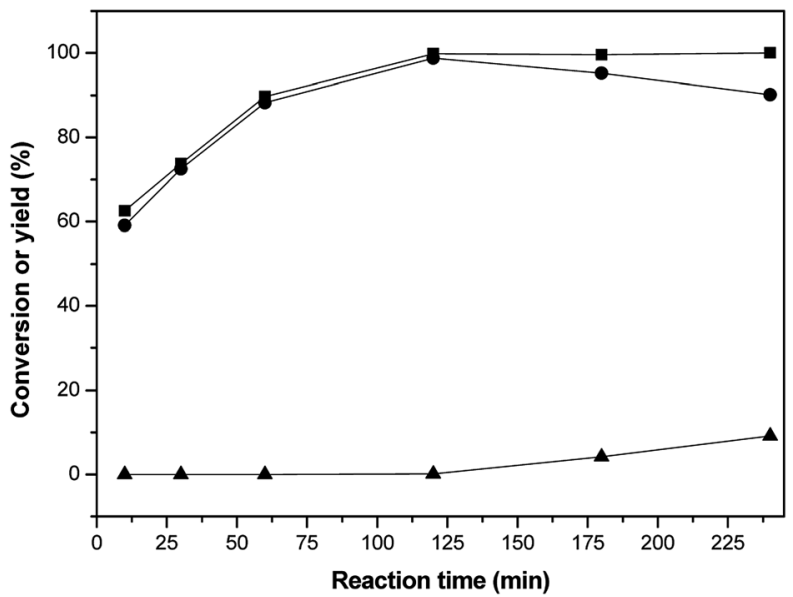

Fig. 4 Isophorone conversions ( $\mathbf{\square}$ ) and the carbon yields of 3,5,5trimethylcyclohexanone (-), and 3,3,5-trimethylcyclohexanol ( $\mathbf{\Delta}$ ) under different reaction times. Reaction conditions: $1.16 \mathrm{~g}$ isophorone, $0.05 \mathrm{~g}$ RANEY® Ni, $2.0 \mathrm{MPa} \mathrm{H}_{2}$ and $10 \mathrm{~mL} \mathrm{THF;} 298 \mathrm{~K}, 1 \mathrm{~h}$.

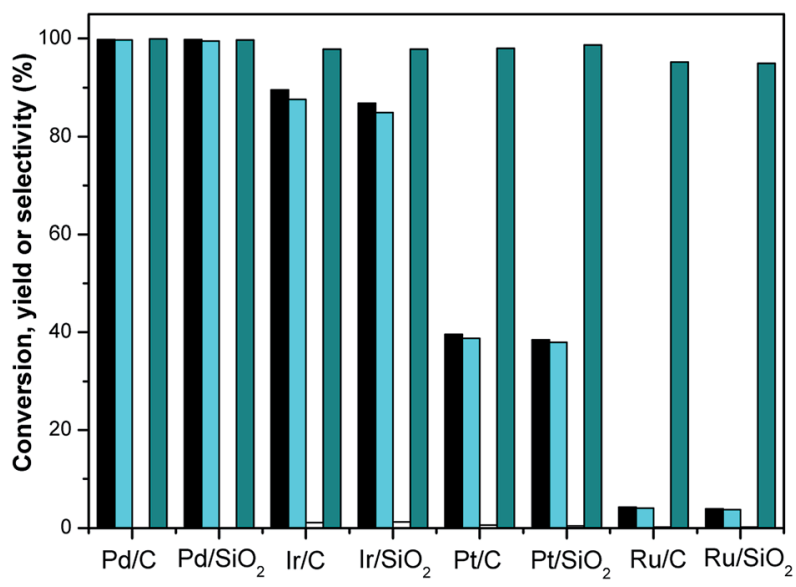

Fig. 5 Isophorone conversions (black bars) and the carbon yields of $\mathrm{TMCH}$ (cyan bars) and 3,3,5-trimethylcyclohexanol (white bars) and selectivity of $\mathrm{TMCH}$ under different catalysts. Reaction conditions: $1.16 \mathrm{~g}$ isophorone, $0.05 \mathrm{~g}$ catalysts (noble metal), 2.0 MPa $\mathrm{H}_{2}$ and $10 \mathrm{~mL}$ THF; $298 \mathrm{~K}, 1 \mathrm{~h}$.

$\mathrm{SiO}_{2}, \mathrm{Pt} / \mathrm{C}, \mathrm{Pt} / \mathrm{SiO}_{2}, \mathrm{Ru} / \mathrm{C}$ and $\mathrm{Ru} / \mathrm{SiO}_{2}$ catalysts. The conversions of isophorone were $89.6 \%$ and $86.8 \%$ over $\mathrm{Ir} / \mathrm{C}$ and $\mathrm{Ir} / \mathrm{SiO}_{2}$, the corresponding yields of TMCH were $87.6 \%$ and $84.9 \%$, respectively. The conversions of isophorone were $39.5 \%$ and $38.4 \%$ over $\mathrm{Pt} / \mathrm{C}$ and $\mathrm{Pt} / \mathrm{SiO}_{2}$, the corresponding yields of $\mathrm{TMCH}$ were $38.7 \%$ and $37.9 \%$, respectively. The results show that the THF solvent can promote the selective hydrogenation of isophorone to TMCH. The selectivity of TMCH is over $94.9 \%$ in THF.

It can be seen from Fig. 6 that the hydrogenation activity order of the catalysts in THF is consistent with that of the solvent-free hydrogenation over RANEY ${ }^{\circledR}$ nickel, $\mathrm{Ni} / \mathrm{SiO}_{2}$, RANEY ${ }^{\circledR}$ cobalt, $\mathrm{Co} / \mathrm{SiO}_{2}$, RANEY® copper, $\mathrm{Cu} / \mathrm{SiO}_{2}$, RANEY® iron, and $\mathrm{Fe} / \mathrm{SiO}_{2}$ catalysts.

The selective hydrogenation of the $\mathrm{C}=\mathrm{C}$ double bond in isophorone was significant improved over RANEY ${ }^{\circledR}$ nickel,

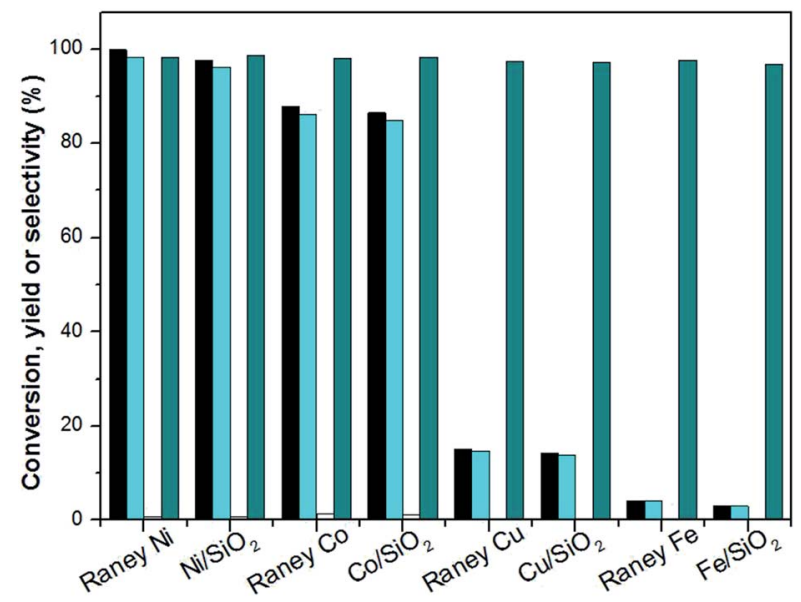

Fig. 6 Isophorone conversions (black bars), the carbon yields of TMCH (cyan bars) and 3,3,5-trimethylcyclohexanol (white bars) and the selectivity of $\mathrm{TMCH}$ under the different catalysts. Reaction conditions: $1.16 \mathrm{~g}$ isophorone, $0.05 \mathrm{~g}$ catalysts, $2.0 \mathrm{MPa} \mathrm{H}_{2}$ and $10 \mathrm{~mL}$ THF; $298 \mathrm{~K}, 1 \mathrm{~h}$.

RANEY® cobalt, RANEY® copper, RANEY® iron, $\mathrm{Ni} / \mathrm{SiO}_{2}, \mathrm{Co} /$ $\mathrm{SiO}_{2}, \mathrm{Cu} / \mathrm{SiO}_{2}$, and $\mathrm{Fe} / \mathrm{SiO}_{2}$ catalysts. The selectivity of 3,3,5-trimethylcyclohexanone was above $96.8 \%$.

In the unsaturated ketone, the THF solvent can promote the selective hydrogenation of the $\mathrm{C}=\mathrm{C}$ double bonds. The nonnoble RANEY $\circledast$ nickel can be used for the selective hydrogenation of isophorone to obtain 3,3,5-trimethylcyclohexanone with a high yield and high selectivity in THF.

Also, the reusability of RANEY® nickel was examined. For this purpose, RANEY ${ }^{\circledR}$ nickel was used repeatedly under optimized conditions ( $0.05 \mathrm{~g}$ catalyst, $10 \mathrm{~mL}$ THF and $2.0 \mathrm{MPa} \mathrm{H}_{2}$, $298 \mathrm{~K}, 120 \mathrm{~min}$ ). RANEY® nickel was recovered by the magnetic adsorption method. After the magnetic adsorption, the reaction liquid was separated by pouring, RANEY® nickel was washed with methanol twice $(5 \mathrm{~mL} \times 2)$, before natural volatilization and air drying. Then, isophorone and tetrahydrofuran were added for the hydrogenation reaction.

The RANEY® nickel was very stable under optimized conditions, as seen in the results shown in Fig. 7. The TMCH yield over the RANEY ${ }^{\circledR}$ nickel differed marginally even after four-fold usage (the slight decline after the fourth run can be rationalized by the catalyst loss during the separation process). Bearing in mind the high activity and good stability of the RANEY® nickel and THF in the hydrogenation reaction of isophorone, we conclude that it may be a good potential hydrogenation method for use in future applications.

\section{Selective hydrogenation of other unsaturated ketones}

To verify the universality of selective hydrogenation of unsaturated ketones in RANEY ${ }^{\circledR} \mathrm{Ni}$ and THF solvent, we also studied the selective hydrogenation of isopropylidene acetone, benzylidene acetone and 6-methyl-5-en-2-one. Selection of the hydrogenation path for different reaction substrates is shown in Scheme 3. The structural characterization of the hydrogenation target products are shown in Fig. S4-S6. $\dagger$ The NMR spectra 


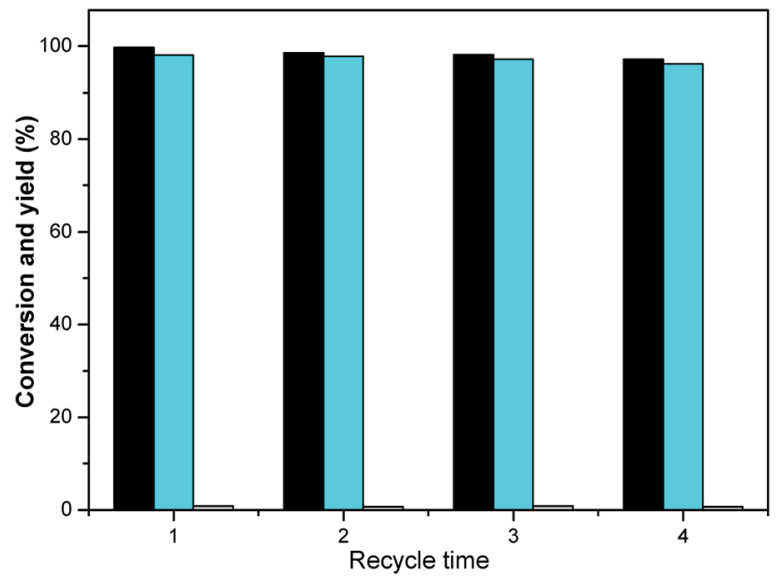

Fig. 7 Conversion of isophorone (black bars) and the carbon yields of TMCH (cyan bars) and 3,3,5-trimethylcyclohexanol (white bars) as a function of the recycling time. Reaction conditions: $1.16 \mathrm{~g}$ isophorone, $0.05 \mathrm{~g}$ RANEY® Ni, $10 \mathrm{~mL}$ THF and $2.0 \mathrm{MPa} \mathrm{H}_{2} ; 298 \mathrm{~K}, 2 \mathrm{~h}$.

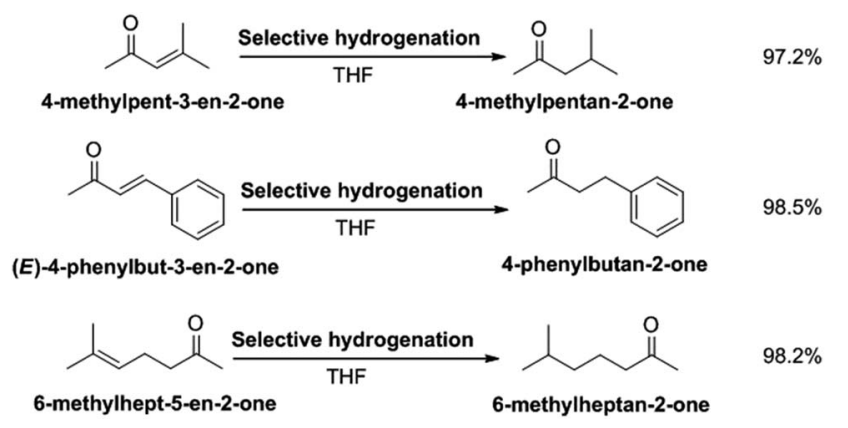

Scheme 3 Selection of the hydrogenation path for different reaction substrates.

(Fig. S4 $\uparrow$ ) of the methyl isobutyl ketone shows the following peaks: ${ }^{1} \mathrm{H}$ NMR $\left(\mathrm{CDCl}_{3}-\mathrm{d}\right), \delta: 2.3-2.31(\mathrm{~d}, 2 \mathrm{H}), 2.13(\mathrm{~s}, 3 \mathrm{H}), 2.09-$ $2.18(\mathrm{~m}, 1 \mathrm{H}), 0.93(\mathrm{~d}, 3 \mathrm{H}), 0.92(\mathrm{~d}, 3 \mathrm{H}) ;{ }^{13} \mathrm{C}$ NMR $\left(\mathrm{CDCl}_{3}-\mathrm{d}\right), \delta$ : 208.8 (1C), 52.8 (1C), 30.2 (1C), $24.4(1 \mathrm{C}), 22.6$ (2C). The methyl isobutyl ketone obtained was in the form of a colorless liquid. The NMR spectra (Fig. S5 $\dagger$ ) of 4-phenylbutyrone shows the following peaks: ${ }^{1} \mathrm{H}$ NMR $\left(\mathrm{CDCl}_{3}-\mathrm{d}\right), \delta: 7.26-7.28(\mathrm{t}, 2 \mathrm{H}), 7.17-$ $7.19(\mathrm{~m}, 3 \mathrm{H}), 2.87-2.90(\mathrm{t}, 2 \mathrm{H}), 2.73-2.76(\mathrm{t}, 2 \mathrm{H}), 2.12(\mathrm{~s}, 3 \mathrm{H}) ;{ }^{13} \mathrm{C}$ NMR ( $\mathrm{CDCl}_{3}$-d), $\delta: 207.7$ (1C), 140.9 (1C), 128.5 (2C), 128.3 (2C), 126.1 (1C), 45.1 (1C), 30.0 (1C), 29.7 (1C). The 6-methyl-2heptanone was a colorless liquid. The methyl isobutyl ketone obtained was in the form of a colorless liquid. The NMR spectra (Fig. S6†) of 6-methyl-2-heptanone shows the following peaks: ${ }^{1} \mathrm{H}$ NMR (CDCl $\left.{ }_{3}-\mathrm{d}\right), \delta: 2.39-2.40(\mathrm{t}, 3 \mathrm{H}), 2.13(\mathrm{~s}, 3 \mathrm{H}), 1.56(\mathrm{~m}$, $3 \mathrm{H}), 1.16$ (s, 2H), 0.87-0.89 (m, 6H); ${ }^{13} \mathrm{C}$ NMR ( $\mathrm{CDCl}_{3}$-d), $\delta: 209.3$ (1C), 43.8 (1C), 38.1 (1C), 29.8 (1C), 27.8 (1C), 22.4 (1C), 21.8 (1C). The 6-methyl-2-heptanone was a colorless liquid.

Under the optimized conditions, the selective hydrogenation of isopropylidene acetone, benzylidene acetone and 6-methyl-5en-2-one were carried out. The yields of 4-methylpentan-2-one, 4-benzylbutan-2-one and 6-methylheptan-2-one were 97.2\%, $98.5 \%$ and $98.2 \%$, respectively. These results indicate that
RANEY ${ }^{\circledR}$ nickel has a good selectivity in THF for the hydrogenation of $\mathrm{C}=\mathrm{C}$ double bonds in unsaturated ketones.

\section{Conclusions}

In this work, the selective hydrogenation of isophorone to TMCH can be performed under RANEY ${ }^{\circledR}$ Ni under solvent-free and solvent conditions. It was found that the THF solvent can promote the selective hydrogenation of isophorone to $\mathrm{TMCH}$. THF can efficiently inhibit further hydrogenation of TMCH. The conversion of isophorone is $100 \%$, and the yield of 3,3,5-trimethylcyclohexanone is $98.1 \%$. The selective hydrogenation of unsaturated ketones was realized by using non-noble metals instead of traditional noble metals. The method was applied to the selective hydrogenation of isopropylidene acetone, benzylidene acetone and 6-methyl-5-ene-2-heptanone. The yield of these target products was over $97.2 \%$. The production cost can be reduced by using RANEY ${ }^{\circledR}$ metal instead of the noble metal palladium. This method has good application prospects.

\section{Conflicts of interest}

There are no conflicts to declare.

\section{Acknowledgements}

This work was supported by Key Scientific Research Plan of Shaanxi Provincial Education Department in 2020 (20JS013, 20JS014) and the Open Project of Shaanxi Key Laboratory of Catalysis (No. SLGPT2019KF01-24).

\section{Notes and references}

1 M. Pisarek, M. Łukaszewski, P. Winiarek, P. Kędzierzawski and M. Janik-Czachor, Appl. Catal., A, 2009, 358, 240.

2 T. Sato, C. V. Rode, O. Sato and M. Shirai, Appl. Catal., B, 2004, 49, 181.

3 F. Chen, N. Li, W. Wang, A. Wang, Y. Cong, X. Wang and T. Zhang, Chem. Commun., 2015, 51, 11876.

4 L. Rodriguez-Garcia, K. Hungerbuhler, A. Baiker and F. Meemken, J. Am. Chem. Soc., 2015, 137, 12121.

5 Y. Hou, S. Ren, M. Niu and W. Wu, R. Soc. Open Sci., 2018, 5, 171523.

6 W. Wang, Y. Liu, N. Li, G. Li, W. Wang, A. Wang, X. Wang and T. Zhang, Sci. Rep., 2017, 7, 6111.

7 L. Faba, E. Díaz and S. Ordóñez, Appl. Catal., B, 2013, 142143, 387.

8 C. P. Kelkar and A. A. Schutz, Appl. Clay Sci., 1998, 13, 417.

9 Y. Liu, K. Sun, H. Ma, X. Xu and X. Wang, Catal. Commun., 2010, 11, 880.

10 F. Xin, W. Dong, Y. Jiang, J. Ma, W. Zhang, H. Wu, M. Zhang and M. Jiang, Crit. Rev. Biotechnol., 2018, 38, 529.

11 C. Su, L. Qi, D. Cai, B. Chen, H. Chen, C. Zhang, Z. Si, Z. Wang, G. Li and P. Qin, Renewable Energy, 2020, 162, 1125.

12 J. Li, Y. Zhang, S. Shi and M. Tu, Biotechnol. Biofuels, 2020, 13, 67. 
13 X. Wang, Z.-T. Zhang, Y. Wang and Y. Wang, Fuel, 2016, 182, 166.

14 C. Xue, M. Liu, X. Guo, E. P. Hudson, L. Chen, F. Bai, F. Liu and S.-T. Yang, Green Chem., 2017, 19, 660.

15 S. Belletante, L. Montastruc, S. Negny and S. Domenech, Biochem. Eng. J., 2016, 116, 195.

16 N. Mahata, A. F. Cunha, J. J. M. Órfão and J. L. Figueiredo, Chem. Eng. J., 2012, 188, 155.

17 S. Ganji, S. Mutyala, C. K. P. Neeli, K. S. R. Rao and D. R. Burri, RSC Adv., 2013, 3, 11533.

18 D. I. Enache, G. J. Hutchings, S. H. Taylor and E. H. Stitt, Catal. Today, 2005, 105, 569.

19 E. Zhan, S. Li, Y. Xu and W. Shen, Catal. Commun., 2007, 8, 1239.

20 S. Li, C. Chen, E. Zhan, S.-B. Liu and W. Shen, J. Mol. Catal. A: Chem., 2009, 304, 88.

21 S. Li, E. Zhan, Y. Li, Y. Xu and W. Shen, Catal. Today, 2008, 131, 347.
22 M. Fodor, A. Tungler and L. Vida, Catal. Today, 2009, 140, 58. 23 N. Györffy and A. Tungler, J. Mol. Catal. A: Chem., 2011, 336, 72.

24 N. Győrffy, A. Tungler and M. Fodor, J. Catal., 2010, 270, 2. 25 S. Mhadgut, M. Torok, J. Esquibel and B. Torok, J. Catal., 2006, 238, 441.

26 J. He, C. Zhao and J. A. Lercher, J. Am. Chem. Soc., 2012, 134, 20768.

27 I. McManus, H. Daly, J. M. Thompson, E. Connor, C. Hardacre, S. K. Wilkinson, N. Sedaie Bonab, J. ten Dam, M. J. H. Simmons, E. H. Stitt, C. D'Agostino, J. McGregor, L. F. Gladden and J. J. Delgado, J. Catal., 2015, 330, 344.

28 C. A. Barrales-Cortés, H. Pérez-Pastenes, J. C. Piña-Victoria and T. Viveros-García, Top. Catal., 2020, 63, 468.

29 R. A. Farrar-Tobar, A. D. Acqua, S. Tin and J. G. de Vries, Green Chem., 2020, 22, 3323.

30 X. Gao, S. Tian, Y. Jin, X. Wan, C. Zhou, R. Chen, Y. Dai and Y. Yang, ACS Sustainable Chem. Eng., 2020, 8, 12722. 